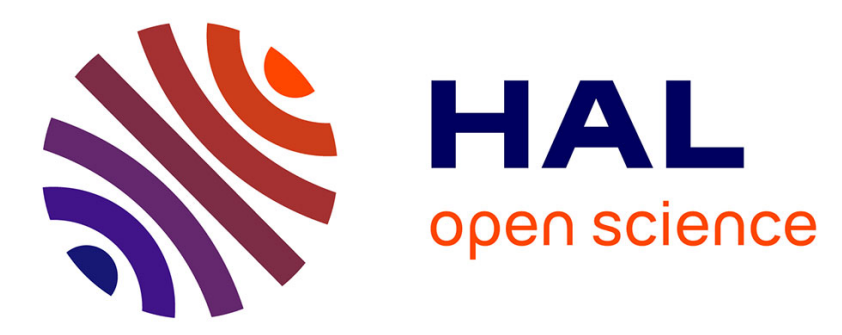

\title{
Social and Ecological Correlates of Parasitic Infections in Adult Male Gray-Cheeked Mangabeys (Lophocebus albigena)
}

Malgorzata E. Arlet, Colin A. Chapman, Lynne A. Isbell, Freerk Molleman, Raivo Mänd, Peeter Hõrak, James R. Carey

\section{To cite this version:}

Malgorzata E. Arlet, Colin A. Chapman, Lynne A. Isbell, Freerk Molleman, Raivo Mänd, et al.. Social and Ecological Correlates of Parasitic Infections in Adult Male Gray-Cheeked Mangabeys (Lophocebus albigena). International Journal of Primatology, 2015, 36 (5), pp.967-986. 10.1007/s10764-015-98669. hal-01217980

\section{HAL Id: hal-01217980 \\ https://hal-univ-rennes1.archives-ouvertes.fr/hal-01217980}

Submitted on 15 Dec 2015

HAL is a multi-disciplinary open access archive for the deposit and dissemination of scientific research documents, whether they are published or not. The documents may come from teaching and research institutions in France or abroad, or from public or private research centers.
L'archive ouverte pluridisciplinaire HAL, est destinée au dépôt et à la diffusion de documents scientifiques de niveau recherche, publiés ou non, émanant des établissements d'enseignement et de recherche français ou étrangers, des laboratoires publics ou privés. 
1

2

3

4 Małgorzata E. Arlet ${ }^{1 *}$, Colin A. Chapman ${ }^{2}$, Lynne A. Isbell ${ }^{3}$, Freerk Molleman ${ }^{4,5}$, Raivo 5 6

$7 \quad{ }^{1}$ Animal and Human Ethology Research Unit, University of Rennes 1, France

$8{ }^{2}$ Department of Anthropology and McGill School of Environment, McGill University,

9 Montréal, Canada, and Wildlife Conservation, Bronx, New York.

$10{ }^{3}$ Department of Anthropology and Animal Behavior Graduate Group, University of

11 California, Davis, USA

$12{ }^{4}$ Ecosystems, Biodiversity and Evolution Research Unit, University of Rennes 1, Rennes,

13 France

$14{ }^{5}$ Department of Zoology, Institute of Ecology and Earth Sciences, University of Tartu, 15 Tartu, Estonia.

$16{ }^{6}$ Department of Entomology, University of California, Davis, CA USA

17 *To whom correspondence should be addressed: M.E. Arlet

18 maarlet@yahoo.com, phone: +33 643244050 


\section{Abstract}

Intestinal parasites may constitute an important evolutionary and ecological force. Our aim

21 was to identify social, physiological, and environmental factors that correlate with intestinal

22 parasite infections in adult male gray-cheeked mangabeys (Lophocebus albigena). We

23 analyzed 102 fecal samples collected over 19 months from 18 adult males for the incidence

24 (proportions of samples with parasites) and intensity (total number of parasites per gram of

25 feces) of infection of nematodes relative to social status, fecal glucocorticoid and

26 testosterone metabolites, group size, and rainfall, all of which are factors that earlier studies

27 suggested can be important mediators of parasite load. Parasite incidence was greater in

28 immigrant males compared to low- and high-ranking males whereas parasite intensity was

29 greater in immigrant males and low-ranking males compared to high-ranking males. Fecal

30 samples with more parasites had higher concentrations of fecal glucocorticoid and

31 testosterone metabolites than fecal samples with fewer parasites. As immigrant males had a

32 greater incidence of parasites and higher concentrations of both metabolites than resident

33 males, this profile appears to fit immigrant males best. We also found higher nematode

34 intensities in mid-sized groups, and during periods with more rainfall. Our results suggest

35 that it will be fruitful for future studies to explore the role of immigrant males as spreaders

36 of intestinal parasites.

37

38 Key words: Nematodes, male rank, fecal glucocorticoids, fecal testosterone, immigrants, 39 helminths 
Arlet et al. p. 3

\section{Introduction}

Parasitic diseases are known to play an important role in animal behavior, ecology, and evolution (Huffman and Chapman 2009; Nunn and Altizer 2006). Intestinal parasites in particular can be major mediators of animal overall body condition, as some are pathogenic and reduce fitness (Huffman and Chapman 2009; Nunn and Altizer 2006). Within species or social groups, parasite loads often vary systematically. Studies of marsupials (Antechinus stuartii) (Bradley et al. 1980) and several other species of mammals (e.g., rodents: Jackson and Farmer 1970; fur seals (Arctocephalus forsteri): Negro et al. 2010; yellow baboons (Papio cynocephalus): Hausfater and Watson 1976; Muller-Graf et al. 1996; mandrills (Mandrillus sphinx): Setchell et al. 2007, 2009) have shown that susceptibility to intestinal parasites can correlate with the host's social and physiological condition. Parasitic infections may be correlated, for example, with host social status, homeostatic imbalance (stress), testosterone level, membership in particular groups, and group size. The relationship between host social status and parasitic infection is complex because these factors can also be influenced directly by the number of intraspecific contacts and the effectiveness of immune defenses (Altizer et al. 2003; Muehlenbein 2009; Sapolsky 1993), which in turn may be influenced by diet and the nature of social contact. Usually, social status is viewed as rank position within a hierarchy based on the outcome of competition over desirable resources (Harcourt 1987; Pusey and Packer 1997; Whitten 1983) but it can also reflect the quality and quantity of previous interactions with others in the group. Immigrants, for example, have a shorter history with their new groups and may be especially challenged as they attempt to fit into the existing hierarchy. Variation in parasitism is assumed to be strongly influenced by variation in social contact (Griffin and 
64 Nunn 2012). Thus, if higher-ranking individuals experience more social contacts they may

65 be more exposed to parasites (Altizer et al. 2003; Møller et al. 1993; Nunn and Altizer

66 2006; Stuart and Strier 1995). Immigrants may also be more exposed to parasites as they

67 move from one group to another (Altizer et al. 2003; Møller et al. 1993). Whether high-

68 ranking individuals or immigrants are at greater risk of parasitic infections may also be

69 influenced by differential access to foods in their habitat. Higher-ranking individuals are

expected to have better access to high quality food that may help boost their immune systems and thus their ability to fight parasitic infections whereas lower-ranking and immigrant individuals may spend more time finding food, and may be more calorically deprived (Sapolsky 2004), with immune systems less able to fight parasitic infections. Challenging social interactions can be associated with long-term exposure to stressors and coping mechanisms (McEwan and Stellar 1993; Sapolsky 2005), thus affecting hormones that can also influence parasitic infections through their effects on the immune system. Cortisol and testosterone are generally considered to suppress immune function, making hosts less effective at controlling infections, including parasitic infections (Bailey and Coe 1999; Braude et al. 1999; Friedman and Lawrence 2002; Muehlenbein 2006). In the case of cortisol, this may occur because although the stress response can be adaptive for immediate threat, chronic stress is pathogenic (Munck et al. 1984). Thus, male mandrills with higher glucocorticoids had a higher diversity of gastrointestinal parasites (Setchell et al. 2010).

In the case of testosterone, while high testosterone levels may facilitate reproductive effort by promoting competitive behavior and muscle anabolism (to aid in mate attraction and competition with conspecifics), it also exhausts resources and inhibits immune 
87 function, thus generating greater opportunities for parasitic infection and increasing

morbidity and mortality (Mougeot et al. 2006; Muehlenbein and Bribiescas 2005; Sheldon and Verhulst 1996; Zuk 1996). Chimpanzees with higher testosterone levels had greater parasite richness (number of species) (Muehlenbein 2006), and fur seals with high testosterone levels had greater numbers of parasite eggs per gram of feces (Negro et al. 2010). In Grant's gazelles (Nanger granti), however, the relationship between testosterone and parasitism varied depending on parasite species (Ezenwa et al. 2012).

Higher levels of testosterone and cortisol are often related to increased levels of aggression in high-rank males (e.g. Arlet et al. 2009a; Barrett et al. 2002; Bercovitch 1993; Cavigelli 2000; Kraus et al. 1999). A positive association between rank and testosterone level was found in male rhesus macaques (Macaca mulatta: Bercovitch 1993; Rose et al. 1975), Japanese macaques (M. fuscata: Barrett et al. 2002), gray-cheeked mangabeys (Arlet et al. 2011), and chimpanzees (Pan troglodytes: Muehlenbein et al. 2004). Thus given the effect of testosterone on immune system suppression, one might expect higher-ranking males to have greater parasite loads than lower-ranking males. Overall, among male vertebrates, this seems to hold true with regard to gastrointestinal helminths (Habig and Archie 2015). Among primates, chimpanzees at Ngogo, Uganda, are consistent with the vertebrate pattern: high-ranking males have higher parasite richness than low-ranking males (Muehlenbein 2006). Yellow baboons (P. cynocephalus) are also consistent, but only during periods of dominance stability (Hausfater and Watson 1976). When the dominance hierarchy was unstable, high-ranking males had lower egg emissions than low-ranking males (Hausfater and Watson 1976). However, no association was found between rank and parasitic infection in a different population of chimpanzees (Seraphin 2000) or in 
populations of olive baboons (Muller-Graf et al. 1996), rhesus macaques (Gordon et al. 1976) and bonobos (P. paniscus: Sannen el al. 2004). In orangutans (Pongo pygmaeus), mandrills, and red jungle fowl (Gallus gallus) dominant males exhibited high testosterone levels and low parasite loads (Thompson et al. 2012; Setchell et al. 2009; Zuk 1996). This may be because testosterone can increase immunocompetence for certain phenotypes (Peters 2000).

To further complicate matters, while testosterone affects behaviors that can cause stress, stress can also influence testosterone levels (Sapolsky 2004). In olive baboons the response of testosterone to stress differed by rank. Testosterone decreased in subordinate males during stressful situations but increased in dominant males (Sapolsky 2005). Thus, there appear to be complex interrelationships between social status, cortisol, testosterone, and parasites, making it difficult to predict who is most vulnerable to parasitic infections.

Larger group size may also increase parasitic infections, the expectation being that larger groups increase the number of social contacts (Griffin and Nunn 2012), but again, the direction does not appear to be uniform. Positive associations have been found between group size and 1) the number of intestinal protozoan species in gray-cheeked mangabeys (Lophocebus albigena) (Freeland 1979), 2) nematode diversity in olive baboons (McGrew et al. 1989) and 3) parasitic infection rate in several Amazonian primates (Davies et al. 1991) but no associations between group size and various measures of parasitism have been found in other studies of primates (Chapman et al. 2009; Nunn 2002a, 2002b; Nunn et al. 2000; Semple et al. 2002; Snaith et al. 2008; Vitone et al. 2004, but see Rifkin et al. 2012). A study of red colobus monkeys (Procolobus rufomitratus) even found a negative correlation between group size and parasite incidence (Snaith et al. 2008). 
Finally, a positive relationship between humidity and parasite infection rate has

134 been suggested for chimpanzees (Huffman et al. 1997; McGrew et al. 1989), olive and

135 Guinea baboons (McGrew et al. 1989), muriquis (Brachyteles arachnoides) (Stuart et al. 136 1993), mantled howler monkeys (Alouatta palliata) (Stuart et al. 1990), and black howler 137 monkeys (A. pigra) (Eckert et al. 2006). Moist conditions appear to promote reinfection 138 and a higher incidence of infections, probably because eggs and larvae survive better in 139 humid environments than in dry ones (Hausfater and Meade 1982). However, some 140 nematode species (e.g., Trichuris spp., Strongyloides spp.) have not shown seasonal 141 variation in infections of primate populations (Huffman et al. 1997; McGrew et al. 1989). Gray-cheeked mangabeys are phylogenetically closely related to the more widely 143 studied baboons (Burrell et al. 2009; Harris and Disotell 1998). Like most baboons, home 144 range overlap is extensive (Janmaat et al. 2009) and females reproduce aseasonally (Arlet et 145 al. 2015). However, they are more arboreal and live in smaller groups, making them 146 valuable for comparative analyses. Adult female gray-cheeked mangabeys usually remain 147 in their natal groups throughout life, whereas males disperse from their natal groups as 148 subadults (Olupot 1999; Olupot and Waser 2001a, 2005). Secondary (breeding) adult male 149 dispersers compete with other males for receptive females and rank as they attempt to join 150 other groups (Olupot and Waser 2001a, 2005). A study of fecal glucocorticoid metabolites 151 (fGCM) showed that immigrant males initially had a mean of 1.38 times higher fGCM 152 profiles than resident males, but over time their FGCM levels had declined and by the end 153 of 6 months were similar to those of resident males (Arlet et al. 2009a). positively correlated with gastrointestinal nematode infections in adult male mangabeys. 
156 We focus on nematodes because they can be noninvasively sampled through collection of 157 fecal samples and can have deleterious effects on health. Some more commonly observed 158 nematodes in wild primates include species of the genera Physaloptera, Enterobius, 159 Trichuris, and Strongylus (Nunn and Altizer 2006). Primates become infected with these worms by the fecal-oral route, ingesting feces or contaminated substrates (soil, vegetation)

161 that contain third-stage larvae (Strongylidae spp.) or first-stage larvae in eggs (Enterobius,

162 Trichuris), through skin contact with infective larvae (Strongylidae spp.), or through

163 ingestion of infected arthropods (Physaloptera; Nunn and Altizer 2006). Although parasites 164 such as Trichuris are typically asymptomatic, heavy infections of Strongyloides are 165 associated with mucosal inflammation, ulceration, dysentery, weight loss, and death

166 (Chapman et al. 2006). Given that parasitic infections have variable associations with social 167 status, physiological condition, group size, and climatic conditions in other primates, we 168 did not establish predictions but conducted an exploratory study about the health of males 169 under different social, physiological, and environmental conditions.

171 Methods

172 Study area and subjects

173 We conducted the study from December 2005 to July 2007 in Kibale National Park, 174 Uganda $\left(0^{\circ} 13^{\prime}-0^{\circ} 41^{\prime} \mathrm{N}\right.$ and $\left.30^{\circ} 19^{\prime}-30^{\circ} 32^{\prime} \mathrm{E}\right)$, near Makerere University Biological Field 175 Station, at Kanyawara. Kibale $\left(795 \mathrm{~km}^{2}\right)$ is a moist, evergreen, medium altitude forest with 176 a mosaic of swamp, grassland, thicket, and colonizing forest (Chapman and Lambert 2000; 177 Struhsaker 1975). Rainfall has a bimodal pattern, with rainy seasons typically in March178 May and August-November, and mean annual rainfall (1990-2001) of 1749 mm (Chapman 
et al. 2002; Valtonen et al. 2013). We collected data on rainfall daily at the Makerere University Biological Field Station.

The mangabey population in Kibale has been studied since the 1970s and multiple groups are well habituated. We collected behavioral data and fecal samples from 18 adult males in five groups (BT1, CC, LC1, LC2, and MK). Group size ranged from 9 to 23 individuals, with 1-9 adult males per group (Arlet et al. 2009a).

We considered an individual male as an adult when he was able to give "whoopgobble" calls, a characteristic call produced only by adult males (Waser 1977a). We observed four adult males individually recognized by color collars from a previous study (Olupot 1999) and 14 animals identified by relative size and distinguishing features (e.g., tail shape, scars, and fractures; Arlet et al. 2009b). Estimating the age of adult males and thus the effect of age on parasite load was not possible because no visible physical markers of male age are available for this species and most males immigrated into our study groups from non-study groups. Nevertheless, we knew that all four collared males were at least 20 years old in 2015 .

\section{Male status}

Earlier studies suggested that mangabey groups lack clear male dominance hierarchies (Olupot and Waser 2005; Waser 1977b), perhaps because reduced visibility between individuals, the complex three-dimensional structure of the forest canopy, and wide group spread reduce both the actual and observed frequency of interactions. However, we have collected sufficient behavioral data to demonstrate the existence of dominance hierarchies in this species (Arlet and Isbell 2009; Arlet et al. 2011). Hierarchies are more 
202 obvious in some smaller groups, while in larger groups two or three males usually have a 203 similar high dominance rank with a high number of reversals. Relative position in the male

204 dominance hierarchy within each group was determined from the outcome of dyadic 205 agonistic interactions, including chases, fights, and supplants during focal samples. This 206 was done for two study periods (December 2005-July 2006, and January-July 2007). We 207 observed 21-257 agonistic interactions per group. Dominance matrices were constructed 208 for each group with rank-order determined by placing winners above losers while 209 minimizing the number of reversals against the hierarchy (i.e., interactions below the 210 diagonal) (Arlet and Isbell 2009; Arlet et al. 2011). The percentage of reversals against the 211 hierarchy was $18.2-25.9 \%$ for four groups where we classified two males as high-ranking 212 (HR) and all other males as low-ranking (LR). In the fifth and largest group (LC1) 37.7-

$21346.1 \%$ of agonistic interactions were reversals. In this group we assigned high rank to three 214 males who won $20 \%$ more fights than other males and low rank to four males who lost 215 more than 33\% fights to these high-ranking males. We measured linearity in five groups 216 using the Landau index h' (for 2006 and 2007, respectively): BT1 ( $h=1, P=0.11 ; \mathrm{h}=0.7$, $217 \mathrm{P}=0.37), \mathrm{CC}(\mathrm{h}=1, \mathrm{P}=0.38 ; \mathrm{h}=0.9, \mathrm{P}=0.38), \mathrm{LC} 1(\mathrm{~h}=0.77, \mathrm{P}=0.003 ; \mathrm{h}=0.75, \mathrm{P}=0.24), \mathrm{LC} 2$ $218(\mathrm{~h}=1, \mathrm{P}=1.0 ; \mathrm{h}=1, \mathrm{P}=0.82), \mathrm{MK}(\mathrm{h}=1, \mathrm{P}=0.38 ; \mathrm{h}=1, \mathrm{P}=1.0)$. Values of $\mathrm{h}$ that are closer to 1 219 indicate greater linearity whereas values closer to 0 indicate the opposite. Landau h values 220 are high in these groups, but with such small group sizes it is not possible to confirm 221 linearity of most dominance hierarchies in most years. Given the high percentage of 222 reversals and the lack of statistically significant linearity, labelling males more precisely 223 than high- or low-rank seems unwarranted. 

were analysed separately based on their status at the time of fecal collection. The number of 247 fecal samples analyzed per individual adult male ranged from 2 to 10, with a median of 5.0.

\section{Immigrant males}

Four males who joined groups during the study were regarded as immigrants.

Three immigrants remained in the study groups for the duration of the study, and one male moved between two groups.

Collection of fecal samples for parasites and hormone analyses

We collected fecal samples from December 2005 to July 2007. We did not collect fecal samples on the first observation day of each period because we did not know what experiences males had during previous days when they were not under observation. After the first day, when a focal individual defecated, the time was noted, the sample was collected within minutes of defecation, placed in a sterile scintillation vial, and stored on ice (for hormone analysis). Approximately 5 grams were placed into $10 \%$ formalin for parasite analysis. At the end of the day, all samples designated for hormonal analyses were placed in $\mathrm{a}-20{ }^{\circ} \mathrm{C}$ freezer until removed for hormone solubilization (Strier and Ziegler 1997; Whitten et al. 1999).

We collected one sample per male per particular day, with time intervals of at least one day between samples from the same male. We aimed to collect samples from the same individuals during both dry and wet seasons. We chose 102 samples from 18 adult males for analysis (Table 1), considering the collection date (to compare the impact of rainfall) and balancing the number of samples from high- and low-rank and immigrant males (for rank and status factors). Two males, PL and MF, changed their status, thus their samples 
249 Analysis of fecal samples for parasites

Samples (5 g of feces) were stored individually in $5.0 \mathrm{ml}$ vials in a $10 \%$ formalin

251 solution. Preserved samples were transported to McGill University (Montreal, Canada),

252 where we examined $1 \mathrm{~g}$ of fecal material for helminth eggs and larvae using concentration

253 by sodium nitrate flotation and fecal sedimentation, primarily sedimentation that involved

254 examining the total sediment (Sloss et al. 1994; C.A. Chapman et al. unpublished data).

255 Parasites were identified on the basis of eggs or larvae color, shape, contents, and size

256 (Jessee et al. 1970). Our ability to identify parasite species from host fecal examination is

257 limited. Consequently, we present our findings at the level of genus when possible and

258 superfamily for the strongyle-type helminths. Measurements were made to the nearest 0.1

259 micron \pm SD using an ocular micrometer fitted to a compound microscope, and

260 representatives were photographed. Egg counts are dependent on a number of host factors,

261 including age and diet (e.g., Stear et al. 1995), limiting the conclusions we can draw using

262 this method. However, it is frequently used to describe infections (e.g., Chapman et al.

263 2006; Ezenwa 2003; Gulland 1992).

We used the term 'nematode incidence', to describe the proportion of individuals

265 infected with Physaloptera, Trichuris, and Strongyloidea spp. We used the term 'nematode

266 intensity' to describe the number of parasites (total numbers of eggs, larvae, and adult

267 stage) per gram of feces per male. In six cases a parasite egg was damaged or we were

268 unable to obtain a good image and these went unidentified.

269 No fecal samples appeared watery or had a discoloration that would suggest illness.

270 Like many previous studies, we assume that gastrointestinal helminth infection influences 
271 overall condition (Chapman et al. 2006; Gillespie et al. 2004; Howells et al. 2010). We

272 conducted parasite analysis from the same fecal mass that was used for fGCM and fTM

273 analyses.

275 Hormone extraction in the field

277 from the same homogenized fecal sample from which the hormones were extracted, by

278 drying these samples to constant weight in the field (Chapman et al. 2006). Our previous

279 study of fGCM (with the same sample set) showed that time of day did not have a

280 significant effect on cortisol concentration in adult male mangabeys (Arlet et al. 2009a).

281 Therefore we analyzed samples both from the mornings and afternoons.

283 colobus (Chapman et al. 2006). A fecal sample was removed from the freezer, thawed, and

284 homogenized using a spatula. Then, $0.50 \mathrm{~g}$ was solubilized using a $5.0 \mathrm{pH}$ citrate

285 buffer/95\% ethanol solution (10 ml, 1:1) that was mixed for $21-27 \mathrm{hrs}$. After mixing,

286 samples were spun in a centrifuge for $30 \mathrm{~min}$ at 3200 rounds per minute to separate the

287 supernatant containing the hormones from the fecal pellet, and then $2 \mathrm{ml}$ of the supernatant

288 was passed through a solid phase extraction cartridge (Alltech maxi-clean filter) for storage

289 and transport (Strier and Ziegler 2005) to the University of Wisconsin.

291 Hormone extraction in the laboratory

The samples were sent to the Wisconsin National Primate Research Center's 
concentration was validated and samples analyzed. At the WNPRC, cortisol and testosterone were extracted from the filters. The cartridges were washed with $1 \mathrm{ml}$ of $20 \%$ methanol and the columns were eluted with $2 \mathrm{ml}$ methanol. This methanol was dried, resuspended in $1 \mathrm{ml}$ ethanol, and $50 \mu \mathrm{l}$ was taken for the enzyme immunoassay. The WNPRC lab used the antibody R4866 for cortisol analysis which were developed by Munro and Stabenfeldt (1984) and are well characterized. The antibody crossreacts 60\% with cortisone (a metabolite of cortisol), 2.5\% with corticosterone and less than $1 \%$ with other steroids (Ziegler et al. 1995). The WNPRC lab used the antibody R159 for testosterone (Munro and Stabenfeldt 1984). The antibody crossreacts $92.4 \%$ with dihydrotestosterone, $11.2 \%$ with 4 -androsten-3beta, 17beta-diol, $5.4 \%$ with dehydroandrosterone, $3.4 \%$ with androstenediol, $2.1 \%$ with androstenedione and less than $1 \%$ with other steroids (Ziegler et al.1995).

An assay comparing serial dilutions of pooled mangabey samples to cortisol standards found no significant difference between the slopes $(\mathrm{t}=-1.62, \mathrm{df}=25, \mathrm{p}>0.05)$. Accuracy was determined by superimposing values from pooled mangabey samples on a standard curve. The mean accuracy over eight pooled samples was 109\% with standard deviation 2.9\%. The inter-assay coefficients of variation were 13.6 and 12.8 for the low and high pools, respectively, and the intra-assay coefficients of variation were 3.9 and 2.1 for the low and high pools, respectively. An assay comparing serial dilutions of pooled mangabey samples to testosterone standards found no significant difference between the slopes $(\mathrm{t}=1.903, \mathrm{df}=26, \mathrm{p}=0.07)$. The mean accuracy over eight pooled samples was $109.19 \%$ with standard deviation $2.17 \%$. The inter-assay coefficients of variation were 10.6 
316 and 11.7 for the low and high pools, respectively, and the intra-assay coefficients of

317 variation were 3.5 and 1.9 for the low and high pools, respectively.

Statistical Analyses

The data represent a count variable that can be described as a Poisson distribution: a

321 few samples had many parasites and $74 \%$ of the samples had no parasites at all. We

322 structured the data by group $(\mathrm{N}=5)$ and by individual/status $(\mathrm{N}=20 ; 18$ males plus 1

323 change of status for 2 males). Group LC1 with its three HR males was included in the 324 analyses.

We performed all analyses using the statistical software R (R Development Core

326 Team 2011). We used Generalized Linear Mixed Models (GLMM), run with the lme4

327 package (Bates et al. 2011) to test with binomial distribution (with logit function) to

328 investigate nematode incidence (proportion of individuals infected) using social status (high

$329 \mathrm{rank} /$ low rank/immigrant), fecal glucocorticoid (fGCM) concentration, fecal testosterone

330 metabolite concentration (fTM), group size, and rainfall as predictor variables. We used

331 GLMM with a Poisson distribution (with log function) to investigate nematode intensity

332 (number of eggs, larvae, and adults per g fecal sample) using the same predictor variables

333 with centered values for fGCM and fTM. We performed post-hoc analyses using ANOVA

334 to investigate possible differences in parasite incidence and intensity among males of

335 different status.

336

337 Ethical Note 
All fecal samples were collected from habituated, wild animals without interfering with their activities. The research complied with with the laws of Uganda and the protocols were approved by the Uganda Wildlife Authority and Uganda National Council for Science and Technology at the time the field research was conducted.

\section{Results}

Correlates of nematode incidence

Overall, the model of nematode incidence was highly significant (likelihood ratio test comparing full and null models: $\chi^{2}=57.02, \mathrm{df}=1, \mathrm{P}<0.001$ ). Nematode incidence was significantly associated with male status, concentrations of fGCM, fTM, and group size but not with rainfall (Table 2).

There was no significant difference in parasite incidence between low- and highranking males (ANOVA: $\mathrm{F}=1.52, \mathrm{df}=1, \mathrm{P}=0.22$ ). However, a greater proportion of immigrant males had parasites than low-ranking (ANOVA: $\mathrm{F}=3.92, \mathrm{df}=1.0, \mathrm{P}=0.05$ ) and high-ranking males (ANOVA: F=13.72, df=1.0, $\mathrm{P}<0.001$; Figure 1). Samples with parasites had higher fGCM and fTM levels than those without parasites (Table 2, Figures 2, 3). Higher than mean $(93.9 \mathrm{ng} / \mathrm{g})$ concentrations of fGCM were observed for $63.9 \%$ of infected samples but only $25.7 \%$ of samples with no parasites. Similarly, higher than mean (62.3 $\mathrm{ng} / \mathrm{g}$ ) concentrations of fTM were observed for $54.4 \%$ of infected samples but only $36.9 \%$ of samples with no parasites. Half of the infected samples came from medium-sized groups (14-16 individuals), whereas the remaining came from larger (18-22 individuals) and smaller groups (fewer than 13 individuals; Figure 4). 
Correlates of nematode intensity

comparing full and null models: $\chi^{2}=453.2$, df $=1, \mathrm{P}<0.001$ ). Nematode intensity (total number of parasites at all life stages/g feces/male) was significantly related to male status,

365 concentrations of fGCM and fTM, group size, and rainfall (Table 3).

Fecal samples from low-ranking and immigrant males were not significantly

367 different in parasite intensity (ANOVA: $\mathrm{F}=3.73, \mathrm{df}=1, \mathrm{P}=0.06$ ) but fecal samples from each

368 had significantly greater nematode intensities than those from high-ranking males

369 (ANOVA: immigrant males $\mathrm{F}=11.62, \mathrm{df}=1.69, \mathrm{P}=0.001$; low-ranking males: $\mathrm{F}=3.85$,

$370 \mathrm{df}=1.71, \mathrm{P}=0.05$; Figure 5).

371 Nematode intensity was significantly related to concentrations of both fGCM and

372 fTM and there was a significant interaction between these two hormone metabolites (Table

373 3): when fTM was higher, then the positive effect of fGCM on parasite intensity was not as

374 strong as predicted by the two combined main effects. Qualitatively, higher fGCM was

375 associated with higher parasite intensity both for samples with low fTM and for samples

376 with high fTM levels (Figure 6). Furthermore, nematode intensity was greatest at

377 intermediate group sizes of 14 to 18 individuals within the group (Table 3, Figure 7).

378 Finally, samples collected during rainy season months had greater nematode intensities than 379 those from dry season months (Table 3, Figure 8). 
Arlet et al. p. 18

Our results show that low-ranking or immigrant status, physiological stress (as measured by fGCM), high concentration of testosterone (as measured by fTM), living in mid-sized groups, and the rainy season all contribute to high nematode infections in adult male gray-cheeked mangabeys. Prolonged stressful conditions can suppress the immune system (Munck et al. 1984), making it easier for parasites to establish themselves. In fact, psychological stress has been shown to increase vulnerability specifically to parasitic infection (Bailey and Coe 1999). Negative associations between cortisol and immune measures have also been found in chimpanzees (Muehlenbein and Watts 2010), yellow and olive baboons (Alberts et al. 1992; Sapolsky and Spencer 1997), and red colobus (Chapman et al. 2006). Conditions for low-ranking males may indeed be stressful. They are, by definition, males who lose more often in competitive interactions with others. Under stable conditions, low-ranking males have higher cortisol levels than high-ranking males in yellow baboons (Sapolsky et al. 1997) and mandrills (Setchell et al. 2010). While we were able to construct dominance hierarchies we also note the high percentage of reversals against the hierarchy in large groups, suggesting that male dominance hierarchies in graycheeked mangabeys are relatively fluid or unstable over time. Such conditions have been shown to increase cortisol levels for those being challenged in, for example, olive baboons (Sapolsky 1992) and rhesus macaques (Higham et al. 2013).

Elsewhere we have shown that immigrant male gray-cheeked mangabeys have higher cortisol levels than resident males (i.e., both high-and low-ranking males), and that this may last for up to six months after males have transferred into a new group (Arlet et al. 2009a). Stressful conditions may manifest early on in the dispersal process. Although dispersing males do not incur increased aggression before leaving their groups (Olupot and 
Waser 2001a), traveling apart from groups appears to increase males' risk of mortality, most likely from crowned eagle (Stephanoaetus coronatus) predation (Olupot and Waser 2001b). Males traveling alone or entering a new group may also lack social support, which is an important mechanism for coping with stressful conditions (Crockford et al. 2008; Wingfield and Sapolsky 2003). Finally, the dispersal phase may expose males to more parasites as the males come into contact with unfamiliar conspecifics harboring different parasites (Chapman et al. 2012; Freeland 1979; VanderWaal et al. 2014a).

We also found that greater nematode incidence and intensity were associated with higher concentrations of fTM. Similar results have been reported for other species (e.g., mandrills: Setchell et al. 2009, chimpanzees: Muehlenbein 2006). Testosterone can have an immunosuppressive effect (Prall and Muehlenbein 2013; Salvador et al. 1996; Weatherhead et al. 1993). However, although dominant males had the highest concentrations of fTM, they had the lowest nematode intensities. It is unclear why, if dominant males have high testosterone, and higher testosterone is associated with higher parasite loads, dominant males did not have high parasite loads. It is possible that in dominant males testosterone has an immunocompetence effect (Peters 2000). Our data suggest that the testosterone signal in parasitic infections might be coming from immigrant males. They had higher mean values of fTM (51.6) and nematode intensity (23.8; Table 1) than low-ranking males (testosterone: 46.6; nematode intensity: 7.3; Table 1). The trend is similar if outlier immigrant male KK, with the highest nematode load, is removed.

We also found that both parasite incidence and intensity were related to group size, as reported in an earlier study of gray-cheeked mangabeys at Kibale (Freeland 1979), however, the mid-sized groups of 14-16 individuals were most infected with nematodes 
428 during our study. We suggest that this pattern is also related to male movements and social 429 interactions. Immigrant males are attracted to groups with more estrous females (Arlet et al.

430 2008; Olupot and Waser 2001a), and the chance of finding fertile females generally

431 increases in larger groups. However, the largest groups may also include more competitors

432 such that immigrant males may be deterred from transferring to them. Thus, mid-sized

433 groups may be 'optimal' for male immigration. In giraffe (Giraffa camelopardalis), which

434 have a fission-fusion social organization structured around social cliques (VanderWaal et

435 al. 2014b), individuals that interact with others outside their social clique have higher

436 parasite loads (VanderWaal et al. 2014a). Our study suggests the same for immigrant male

437 gray-cheeked mangabeys. The high frequency of social interactions between immigrant

males and estrous females may also make such males parasite spreaders, exposing members

439 of their new groups to parasites obtained from their former groups.

$440 \quad$ Finally, we found that parasite intensity was positively correlated with rainfall. Our

441 results are thus consistent with what is known about the effects of climatic conditions on

442 parasites (e.g., Huffman et al. 1997; McGrew 1989; Stuart et al. 1993).

In summary, our results repeatedly point to immigrant males as important vessels

444 for nematode infection in gray-cheeked mangabey populations. In the future it would be

445 beneficial to investigate the social aspects of parasite transmission. Social networks

446 analyses have recently been employed to document that gut bacteria can be socially

447 transmitted in yellow baboons (Tung et al. 2015) and to identify who is most likely to

448 spread bacterial and helminth infections in giraffes (VanderWaal et al. 2014a). This

449 approach may be especially fruitful in elucidating in greater detail the role of immigrant 
male gray-cheeked mangabeys specifically, and immigrants in general, in parasite transmission.

\section{Acknowledgments}

We thank the Uganda Wildlife Authority, Uganda National Council for Science and Technology and personnel at the Makerere University Biological Field Station for permission to work in Kibale National Park. We thank field assistants Akora Charles, Katusebe Swaibu, Kaseregenyu Richard, Koojo John, and Sabiti Richard for their invaluable assistance in the field. We thank Chesley Walsh and Johanna Bleecker for parasite analyses and Ants Kaasik and Veronique Biquand for advice on the statistical analyses. Finally, we appreciate the comments and suggestions by the editor and two anonymous reviewers that greatly improved the manuscript.

\section{References}

Alberts, S.C., Sapolsky, R.M., \& Altmann, J. (1992). Behavioral, endocrine, and immunological correlates of immigration by an aggressive male into a natural primate group. Hormones and Behavior 26, 167-178.

Altizer, S., Nunn, C.L., Thrall, P.H., Gittleman, J.L., Antonovics, J., Cunningham, A.A., Dobson, A.P., Ezenwa, V., Jones K,E., Pedersen, A.B., Poss, M., \& Pulliam, J.R.C. (2003). Social organization and parasite risk in mammals: integrating theory and empirical studies. Annual Review of Ecology, Evolution, and Systematics 34, 517547. 
472 Arlet, M.E., Carey, J.R., \& Molleman, F. (2009b). Species and sex differences in type and frequencies of injuries and impairments among four arboreal primate species in Kibale National Park, Uganda. Primates 50, 65-73.

Arlet, M.E., Grote, M.N., Isbell, L.A., Molleman, F., \& Carey, J.R. (2009a). Reproductive tactics influence cortisol levels in individual male mangabeys (Lophocebus albigena). Hormones and Behavior 55, 210-216.

Arlet, M.E., \& Isbell, L.A. (2009). Variation in behavioral and hormonal responses of adult male mangabeys (Lophocebus albigena) to crowned eagles (Stephanoaetus coronatus) in Kibale National Park, Uganda. Behavioral Ecology and Sociobiology 63, 491-499.

Arlet, M.E., Isbell, L.A., Kaasik A., Molleman, F., Chancellor, R.L., Chapman, C.A., Mänd, R., \& Carey, J.R. (2015). Determinants of reproductive performance among female gray-cheeked mangabeys (Lophocebus albigena) in Kibale National Park, Uganda. International Journal of Primatology 36, 55-73.

Arlet, M.E., Kaasik, A., Molleman., F., Isbell, L.A., Carey, J.R., \& Mänd, R. (2011). Social factors increase fecal testosterone levels in wild male gray-cheeked mangabeys (Lophocebus albigena). Hormones and Behavior 59, 605-611.

Arlet, M.E., Molleman, F., \& Chapman, C.A. (2008). Mating tactics in male grey-cheeked mangabeys (Lophocebus albigena). Ethology 114, 841-852.

Bailey, M.T., \& Coe, C.L. (1999). Maternal separation disrupts the integrity of the intestinal microflora in infant rhesus monkeys. Developmental Psychology 35, 146155. 
Barrett, G.M., Shimizu, K., Bardi, M., Asaba, S., \& Mori, A. (2002). Endocrine correlates of rank, reproduction, and female-directed aggression in male Japanese macaques (Macaca fuscata). Hormones and Behavior 42, 85-96.

Bercovitch, F.B. (1993). Dominance rank and reproductive maturation in rhesus macaques (Macaca mulatta). Journal of Reproduction and Fertility 99, 113-120.

Bradley, A.J., McDonald, I.R., \& Lee, A.K. (1980). Stress and mortality in a small marsupial (Antechinus stuartii, Macleay). General and Comparative Endocrinology 40, 188-200.

Braude, S., Tang-Martinez, Z., \& Taylor, G.T. (1999). Stress, testosterone and the immunoredistribution hypothesis. Behavioral Ecology 10, 345-350.

Bribiescas, R.G. (2001). Reproductive ecology and life history of the human male. Yearbook of Physical Anthropology 44, 148-176.

Burrell, A.S., Jolly, C.J., Tosi, A.J., \& Disotell T.R. (2009). Mitochondrial evidence for the hybrid origin of the kipunji, Rungwecebus kipunji (Primates: Papionini). Molecular Phylogenetics and Evolution 51, 340-348.

Cavigelli, S.A., \& Pereira, M.E. (2000). Mating season aggression and fecal testosterone levels in male ring-tailed lemurs (Lemur catta). Hormones and Behavior 37, 246-278.

Chapman, C.A., Bowman, D.D., Ghai, R.R., Goldberg, T.L., Gogarten, J.F., Rothman, J.M., Twinomugisha, D., \& Walsh, C. (2012). Protozoan parasites in group-living primates: Testing the biological island hypothesis. American Journal of Primatology $74,510-517$. 
515 Chapman, C.A., Chapman, L.J., \& Gillespie, T.R. (2002). Scale issues in the study of primate foraging: red colobus of Kibale National Park. American Journal of Physical Anthropology 117, 349-363.

Chapman, C.A., \& Lambert, J.E. (2000). Habitat alteration and the conservation of African primates: a case study of Kibale National Park, Uganda. American Journal of Primatology 50, 169-186.

Chapman, C.A., Rothman, J.M., \& Hodder, S.A.M. (2009). Can parasites be a selective force influencing primate group size?: A test with red colobus. In M.A. Huffman \& C.A. Chapman, (Eds.) Primate parasite ecology: The dynamics and study of hostparasite relationships. Cambridge studies in biological and evolutionary anthropology (pp. 423-440). Cambridge: Cambridge University Press.

Chapman, C.A., Wasserman, M.D., Gillespie, T.R., Speirs, M.L., Lawes, M.J., Saj, T.L., \& Ziegler, T.E. (2006). Do food availability, parasitism, and stress have synergistic effects on red colobus populations living in forest fragments? American Journal of Physical Anthropology 131, 525-534.

Crockford, C., Wittig, R.M., Whitten, P.L., Seyfarth, R.M,, \& Cheney, D.L. (2008). Social stressors and coping mechanisms in wild female baboons (Papio hamadryas ursinus). Hormones and Behavior 53, 254-265.

Davies, C.R., Ayres, J.M., Dye, C., \& Deane, L.M. (1991). Malaria infection rate of Amazonian primates increases with body weight and group size. Functional Ecology 5, 655-662. 
536 Eckert, K.A., Hahn, N.E., Genz, A., Kitchen, D.M., Stuart, M.D., Averbeck, G.A., 537 Stromberg, B.E., \& Markowitz, H. (2006). Coprological surveys of Alouatta pigra at two sites in Belize. International Journal of Primatology 27, 227-238.

Ezenwa, V.O. (2003). Habitat overlap and gastrointestinal parasitism in sympatric African bovids. Parasitology 126, 379-388.

Ezenwa, V.O., Ekernas, L.S., \& Creel, S. (2012). Unravelling complex associations between testosterone and parasite infection in the wild. Functional Ecology 26, 123 133.

Freeland, W.J. (1979). Primate social groups as biological islands. Ecology 60, 719-728.

Friedman, E.M., \& Lawrence, D.A. (2002). Environmental stress mediates changes in neuroimmunological interactions. Toxicological Sciences 67, 4-10.

Gillespie, T.R., Greiner, E.C., \& Chapman, C.A. (2004). Gastrointestinal parasites of the guenons of western Uganda. Journal of Parasitology 90, 1356-1360.

Griffin, R.H., \& Nunn, C.L. (2012). Community structure and the spread of infectious disease in primate social networks. Evolutionary Ecology 26, 779-800.

Gordon, T.P., Rose, R.M., \& Bernstein, I.S. (1976). Seasonal rhythm in plasma testosterone levels in the rhesus monkey (Macaca mulatta): a three-year study. Hormones and Behavior 98, 168-175.

Gulland, F.M.D. (1992). The role of nematode parasites in Soay sheep (Ovis aries L.) mortality during a population crash. Parasitological Research 105, 493-503.

Habig, B. \& Archie, E.A. (2015). Social status, immune response and parasitism in males: a meta-analysis. Philosophical Transactions of the Royal Society B 370, 20140109. 
Arlet et al. p. 26

558 Harcourt, A.H. (1987). Dominance and fertility among female primates. Journal of $559 \quad$ Zoology, London 213, 471-487.

560 Harris, E.E., \& Disotell, T.R. (1998). Nuclear gene trees and the phylogenetic relationships 561 of the mangabeys (Primaes: Papionini). Molecular Biology and Evolution 15, 892-

562

Hausfater, G., \& Meade, B.J. (1982). Alternation of sleeping groves by yellow baboons 564 (Papio cynocephalus) as a strategy for parasite avoidance. Primates 23, 287-297.

Hausfater, G., \& Watson, D.F. (1976). Social and reproductive correlates of parasite ova emissions by baboons. Nature 262, 688-689.

567

568

569

570

571

572 900.

Higham, J.P., Heistermann, M., \& Maestripieri, D. (2013). The endocrinology of male rhesus macaque social and reproductive status: a test of the challenge and social stress hypotheses. Behavioral Ecology and Sociobiology 67, 19-30.

Howells, M.E., Pruetz, J., \& Gillespie, T.R. (2010). Patterns of gastro-intestinal parasites and commensals as an index of population and ecosystem health: the case of sympatric western chimpanzees (Pan troglodytes verus) and Guinea baboons (Papio hamadryas papio) at Fongoli, Senegal. American Journal of Primatology 71, 1-7.

Huffman, M.A. (1997). Current evidence for self-medication in primates: A multidisciplinary perspective. Yearbook of Physical Anthropology 40, 171-200.

Huffman, M.A., \& Chapman, C.A. (2009). Primate parasite ecology: the dynamics and study of host-parasite relationships. Cambridge: Cambridge University Press.

Jackson, L.A., \& Farmer, J.N. (1970). Effect of host fighting behavior on the course of infection of Trypanosoma duttoni in mice. Ecology 51, 672-679. 
Janmaat, K.R., Olupot, W., Chancellor, R.L., Arlet, M.E., \& Waser, P.M. (2009). Longterm site fidelity and individual home range shifts in grey-cheeked mangabeys. International Journal of Primatology 30, 443-466.

Jessee, M.T., Schilling, P.W., \& Stunkard, J.A. (1970). Identification of intestinal helminth eggs in Old World primates. Laboratory Animal Care 20, 83-87.

Kraus, C., Heistermann, M., \& Kappeler, P.M. (1999). Physiological suppression of sexual function of subordinate males: a subtle form of intrasexual competition among male sifakas (Propithecus verreauxi)? Physiology and Behavior 66, 855-861.

McGrew, W.C., Tutin, C.E.G., Collins, D.A., \& File, S.K. (1989). Intestinal parasites of sympatric Pan troglodytes and Papio spp. at two sites: Gombe (Tanzania) and Mt. Assirik (Senegal). American Journal of Primatology 17, 147-155.

Møller, A., Dufva, R., \& Allander, K. (1993). Parasites and the evolution of host social behavior. Advances in the Study of Behavior 22, 65-102.

Mougeot, F., Redpath, S.M., \& Piertney, S. (2006). Elevated spring testosterone increases parasite intensity in male red grouse. Behavioral Ecology 17, 117-125.

Muehlenbein, M.P. (2006). Intestinal parasite infections and fecal steroid levels in wild chimpanzees. American Journal of Physical Anthropology 130, 546-550.

Muehlenbein, M.P. (2009). The application of endocrine measures in primate parasite ecology. In M.A. Huffman \& C.A, Chapman CA (Eds.), Primate parasite ecology: the dynamics and study of host-parasite relationships. Cambridge: Cambridge University Press.

Muehlenbein, M.P., \& Bribiescas, R.G. (2005). Testosterone-mediated immune functions and male life histories. American Journal of Human Biology 17, 527-558. 
603 Muehlenbein, M.P., \& Watts, D.P. (2010). The costs of dominance: testosterone, cortisol 604 and intestinal parasites in wild male chimpanzees. BioPsychoSocial Medicine 4, 21

605 Muehlenbein, M.P., Watts, D.P., \& Whitten, P.L. (2004). Dominance rank and fecal 606 testosterone in adult male chimpanzees (Pan troglodytes scheinfurthii) at Ngogo, Kibale National Park, Uganda. American Journal of Primatology 64, 71-82.

608 609

Muller-Graf, C.D.M., Collins, D.A., \& Woolhouse, M.E.J. (1996). Intestinal parasite burden in five troops of olive baboons (Papio cynocephalus anubis) in Gombe Stream National Park, Tanzania. Parasitology 112, 489-497.

Munck, A., Guyre, P., \& Holbrook, N. (1984). Physiological functions of glucocorticoids during stress and their relation to pharmacological actions. Endocrine Reviews 5, 2547.

Munro, C., \& Stabenfeldt, G. (1984). Development of cortisol enzyme immunoassay in plasma. Clinical Chemistry 31, 985.

Negro, S.S., Caudron, A.K., Dubois, M., Delahaut, P., \& Gemmell, N.J. (2010). Correlation between male social status, testosterone levels, and parasitism in a dimorphic polygynous mammal. PLoS ONE DOI: 10.1371/journal.pone.0012507.

Nunn, C.L. (2002a). A comparative study of leukocyte counts and disease risk in primates. Evolution 56, 177-190.

Nunn, C.L. (2002b). Spleen size, disease risk and sexual selection: a comparative study in primates. Evolutionary Ecology Research 4, 91-107.

Nunn, C.L., \& Altizer, S.M. (2006). Infectious diseases in primates: behavior, ecology and evolution. Oxford: Oxford University Press. 
625 Nunn, C.L., Gittelman, J.L., \& Antonovics, J. (2000). Promiscuity and the primate immune

626

627 628

629 630

631

632 633 system. Science 290, 1168-1170.

Olupot, W. (1999). Mangabey dispersal and conservation in Kibale Forest National Park, Uganda. Dissertation. Indiana: Purdue University.

Olupot, W., \& Waser, P.M. (2001a). Correlates of intergroup patterns in male grey-cheeked mangabeys. International Journal of Primatology 22, 169-187.

Olupot, W., \& Waser, P.M. (2001b). Activity patterns, habitat use and mortality risks of mangabey males living outside social groups. Animal Behaviour 61, 1227-1235.

Olupot, W., \& Waser, P.M. (2005). Patterns of male residency and inter-troop transfer in mangabeys (Lophocebus albigena). American Journal of Primatology 66, 331-349.

Peters, A. (2000). Testosterone treatment is immunosuppressive in superb fairy-wrens, yet free-living males with high testosterone are more immunocompetent. Proceedings of the Royal Society of London, B: Biological Sciences 267, 883-889.

Prall, S.P., \& Muehlenbein, M.P. (2013). Testosterone and immune function in primates: A brief summary with methodological considerations. International Journal of Primatology 35, 805-824.

Pusey A., \& Packer, C. (1997). The ecology of relationships. In J.R. Krebs \& N.B. Davies (Eds.), Behavioural ecology: an evolutionary approach, $4^{\text {th }}$ ed. (pp. 254-284). New York: Blackwell.

Rifkin, J.L., Nunn, C.L., \& Garamszegi, L.Z. (2012). Do animals living in larger groups experience greater parasitism? A meta-analysis. American Naturalist 180, 70-82.

Rose, R.M., Bernstein, I.S., \& Gordon, T.P. (1975). Consequences of social conflict on plasma testosterone levels in rhesus monkeys. Psychosomatic Medicine 37, 50-60. 
648 Salvador, A., Veiga, J.P., Martin, J., Lopez, P., Abelenda, M., \& Puerta, M. (1996). The

649

650

651

652

653

654

655

656

657

658

659

660

661

662

663

664

665

666

667

668

669

670 cost of producing a sexual signal: testosterone increases the susceptibility of male lizards to ectoparasite infestation. Behavioral Ecology 7, 145-150.

Sannen, A., van Elsacker, L., Heistermann, M., \& Eens, M. (2004). Urinary testosteronemetabolite levels and dominance rank in male and female bonobos (Pan paniscus). Primates 45, 89-96.

Sapolsky, R.M. (1992). Cortisol concentrations and the social significance of rank instability among wild baboons. Psychoneuroendocrinology 17, 701-709.

Sapolsky, R.M. (1993). Neuroendocrinology of the stress-response In J.B. Becker, S.M. Breedlove, \& D. Crews (Eds.), Behavioral endocrinology (pp. 287-324). Cambridge: The MIT Press.

Sapolsky, R.M. (2004). Social status and health in humans and other animals. Annual Review of Anthropology 33, 393-418.

Sapolsky, R.M. (2005). The influence of social hierarchy on primate health. Science 5722, 648-652.

Sapolsky, R.M., Alberts, S.C., \& Altmann, J. (1997). Hypercortisolism associated with social subordinance or social isolation among wild baboons. Archives of General Psychiatry 54, 1137-1143.

Sapolsky, R.M., \& Spencer, E.M. (1997). Insulin-like growth factor I is suppressed in socially subordinate male baboons. American Journal of Physiology 273, 1347-1351.

Semple, S., Cowlishaw, G., \& Bennett, P.M. (2002). Immune system evolution among anthropoid primates: parasites, injuries and predators. Proceedings of the Royal Society of London, B: Biological Sciences 269, 1031-1037. 
671 Seraphin, S.B. (2000). The reproductive ecology and stress physiology of free-ranging male

672

673

674

675

676

677

678

679

680

681

682

683

684

685

686

687

688

689

690

691 chimpanzees in Budongo Forest, Uganda. Master's thesis. Oxford: Oxford University.

Setchell, J.M., Bedjabaga, I.B,, Goossens, B., Reed, P., Wicking, E.J., \& Knapp, L.A. (2007). Parasite prevalence, abundance, and diversity in a semi-free-ranging colony of Mandrillus sphinx. International Journal of Primatology 28, 1345-1362.

Setchell, J.M., Charpentier, M., Abbott, K.A., Wickings, E.J., \& Knapp, L.A. (2009). Is brightest best? Testing the Hamilton-Zuk hypothesis in mandrills. International Journal of Primatology 30, 825-844.

Setchell, J.M., Smith, T., Wickings, E.J., \& Knapp, L.A. (2010). Stress, social behaviour, and secondary sexual traits in a male primate. Hormones and Behavior 58, 720-728.

Sheldon, B.C., \& Verhulst, S. (1996). Ecological immunology: costly parasite defenses and trade-offs in evolutionary ecology. Trends in Ecology and Evolution 11, 317-321.

Sloss, M.W., Kemp, R.L., \& Zajac, A.M. (1994). Veterinary clinical parasitology (6th ed.). Ames: Iowa State University Press.

Snaith, T.V., Chapman, C.A., Rothman, J.M., \& Wasserman, M.D. (2008). Bigger groups have fewer parasites and similar cortisol levels: a multi-group analysis in red colobus monkeys. American Journal of Primatology 70, 1072-1080.

Stear, M.J., Bairden, K., Bishop, S.C., Duncan, J.L., Karimi, S.K., McKellar Q, \& Murray, M. (1995). Different patterns of faecal egg output following infection of Scottish blackface lambs with Ostertagia circumcincta. Veterinary Parasitology 59, 29-38. 
Strier, K.B., \& Ziegler, T.E. (1997). Behavioral and endocrine characteristics of the reproductive cycle in wild muriqui monkeys, Brachyteles arachnoides. American Journal of Primatology 67, 1-4.

Struhsaker, T.T. (1975). The red colobus monkey. Chicago: University of Chicago Press.

Stuart, M.D., Greenspan, L.L., Glander, K.E., \& Clarke, M.R. (1990). Coprological survey of parasites of wild mantled howling monkeys, Alouatta palliata palliata. Journal of Wildlife Diseases 26, 547-549.

Stuart, M.D., \& Strier, K.B. (1995). Primates and parasites: A case for a multidisciplinary approach. International Journal of Primatology 16, 577-593.

Stuart, M.D., Strier, K.B., \& Pierberg, S.M. (1993). A coprological survey of parasites of wild muriquis Brachyteles arachnoides and brown howling monkeys Alouatta fusca. Journal of the Helminthological Society of Washington 60, 111-115.

Thompson, M.E., Zhou, A., \& Knott, C.D. (2012). Low testosterone correlates with delayed development in male orang-utans. PLOS ONE 7: e47282. doi:10.1371/journal.pone.0047282.

Tung, J., Barreiro, L.B., Burns, M.B., Grenier, J.-C., Lynch, J., Grieneisen, L.E., Altmann, J., Alberts, S.C., Blekhman, R., \& Archie, E.A. (2015). Social networks predict gut microbiome composition in wild baboons. eLife 10.7554/eLife.05224.

Valtonen, A., Molleman, F., Chapman, C.A., Carey, J.R., Ayres, M.P., \& Roininen, H. (2013). Tropical phenology: bi-annual rhythms and interannual variation in an Afrotropical butterfly assemblage. Ecosphere 4, 1-28. 
VanderWaal, K.L., Atwill, E.R., Isbell, L.A., \& McCowan, B. (2014a). Linking social and pathogen transmission networks using microbial genetics in giraffe (Giraffa camelopardalis). Journal of Animal Ecology 83, 406-414.

VanderWaal, K.L., Wang, H., McCowan, B., Fushing, H., \& Isbell, L.A. (2014b). Multilevel social organization and space use in reticulated giraffe (Giraffa camelopardalis). Behavioral Ecology 25, 17-26.

Vitone, N.D., Altizer, S.M., \& Nunn, C.L. (2004). Body size, diet and sociality influence the species richness of parasitic worms in anthropoid primates. Evolutionary Ecology Research 6, 1-17.

Waser, P.M. (1977a). Individual recognition, intragroup cohesion and intergroup spacing: evidence from sound playback to forest monkeys. Behaviour 60, 27-74.

Waser, P.M. (1977b). Feeding, ranging and group size in the mangabey, Cercocebus albigena. In T.H. Clutton-Brock (Ed.), Primate ecology (pp. 183-222). London: Academic Press.

Weatherhead, P.J., Metz, K.J., Bennett, G.F., \& Irwin, R.E. (1993). Parasite faunas, testosterone and secondary sexual traits in male red-winged blackbirds. Behavioral Ecology and Sociobiology 33, 13-23.

Welle, S., Jozefowicz, R., Forbes, G., Riggs, R.C. (1992). Effect of testosterone on metabolic rate and body composition in normal men and men with muscular dystrophy. Journal of Clinical Endocrinology and Metabolism 74, 332-335.

Whitten, P.L. (1983). Diet and dominance among female vervet monkeys (Cercopithecus aethiops). American Journal of Primatology 5, 139-159. 
735 Whitten, P.L., Brockman, D.K., \& Stavisky, R.C. (1998). Recent advances in noninvasive 736 techniques to monitor hormone-behavior interactions. Yearbook of Physical Anthropology 41, 1-23.

738 Wingfield, J.C., \& Sapolsky, R.M. (2003). Reproduction and resistance to stress: when and 739 how. Journal of Neuroendocrinology 15, 711-724.

740 Ziegler, T.E., Scheffler, G., \& Snowdon, C.T. (1995). The relationship of cortisol levels to social environment and reproductive functioning in female cotton-top tamarins Saguinus oedipus. Hormones and Behavior 29, 407-424.

743 Zuk, M. (1996). Disease, endocrine-immune interactions, and sexual selection. Ecology 7 , 744 $1037-1042$. 
Arlet et al. p. 35

$746 \quad$ Figure Legends

747

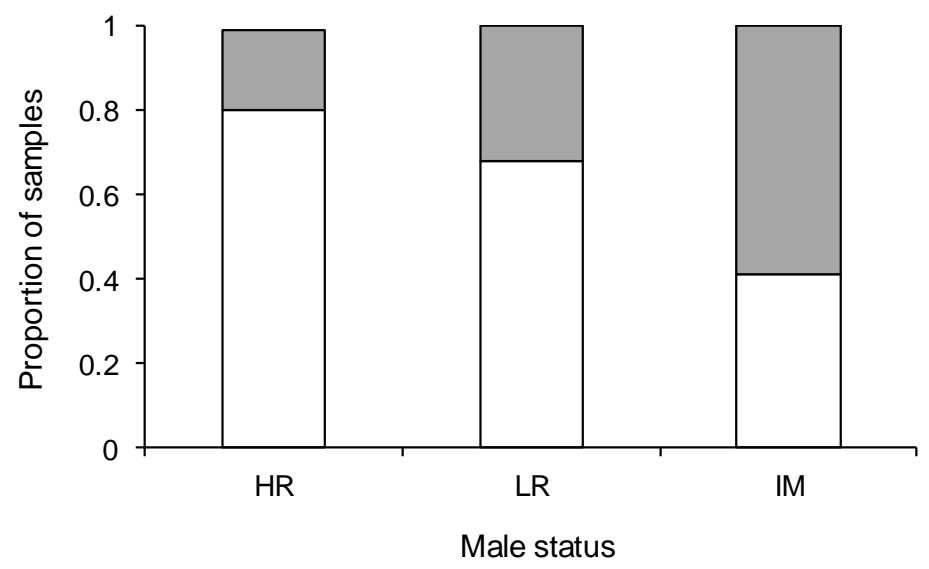

748

749 Fig.1 Nematode incidence (proportion of samples with parasites) in male gray-cheeked

750 mangabeys relative to male status (HR/LR/M) in Kibale National Park, Uganda, 2006-

751 2007. Shaded proportions are those with parasites; white proportions are those without

752 parasites. $\mathrm{HR}=$ high-ranking males, $\mathrm{LR}=$ low-ranking males, $\mathrm{IM}=$ immigrant males.

753 Shaded proportions are those with parasites; white proportions are those without parasites 
Arlet et al. p. 36

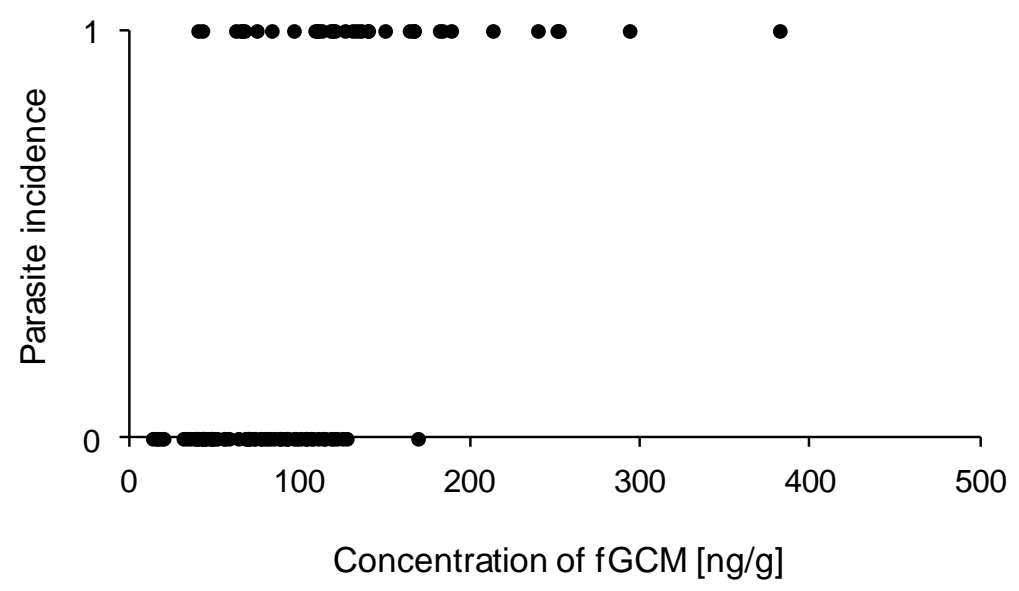

755

756 Fig. 2 Samples with and without parasites in male gray-cheeked mangabeys relative to

757 concentrations of fecal glucocorticoid metabolite in Kibale National Park, Uganda, 2006-

$758 \quad 2007$

759

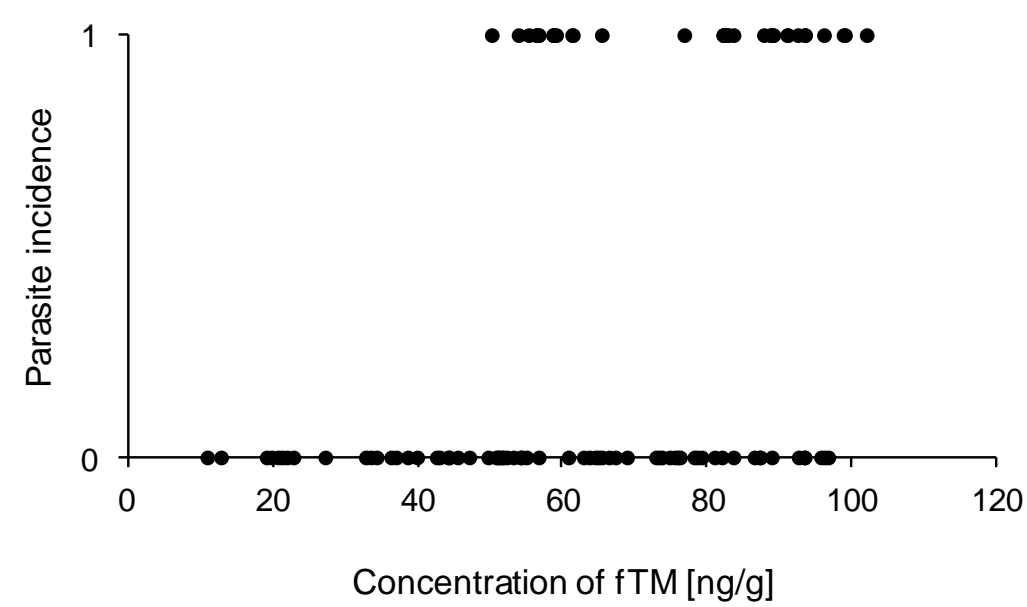

761 Fig. 3 Samples with and without parasites in male gray-cheeked mangabeys relative to

762 concentrations of fecal testosterone metabolite in Kibale National Park, Uganda, 2006-2007 
Arlet et al. p. 37

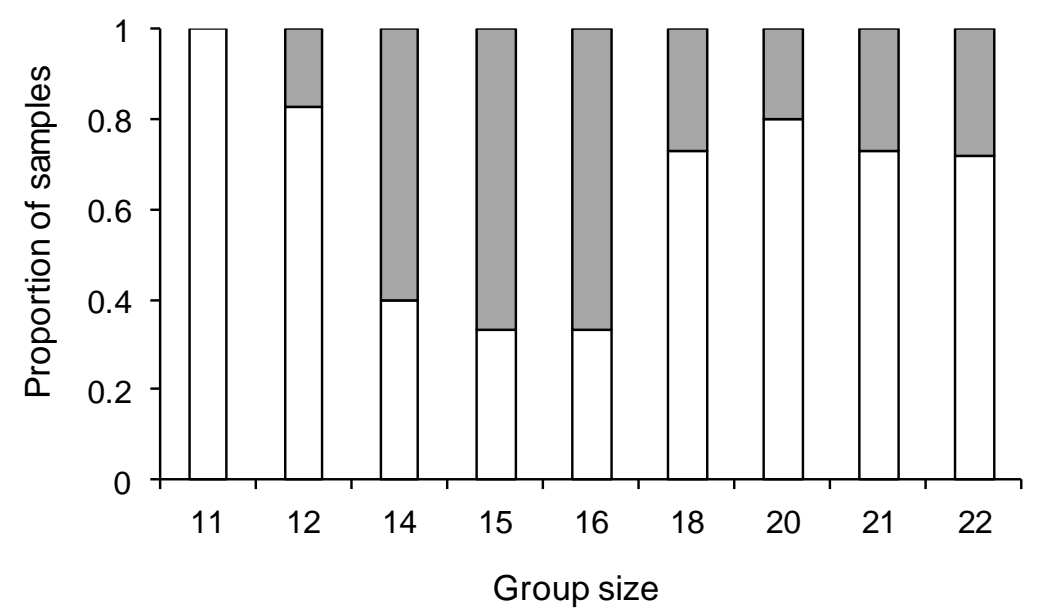

763 Fig.4 Nematode incidence (proportion of samples with parasites) in male gray-cheeked

764 mangabeys relative to group size in Kibale National Park, Uganda, 2006-2007. Shaded

765 proportions are those with parasites; white proportions are those without parasites

766

767 
Arlet et al. p. 38

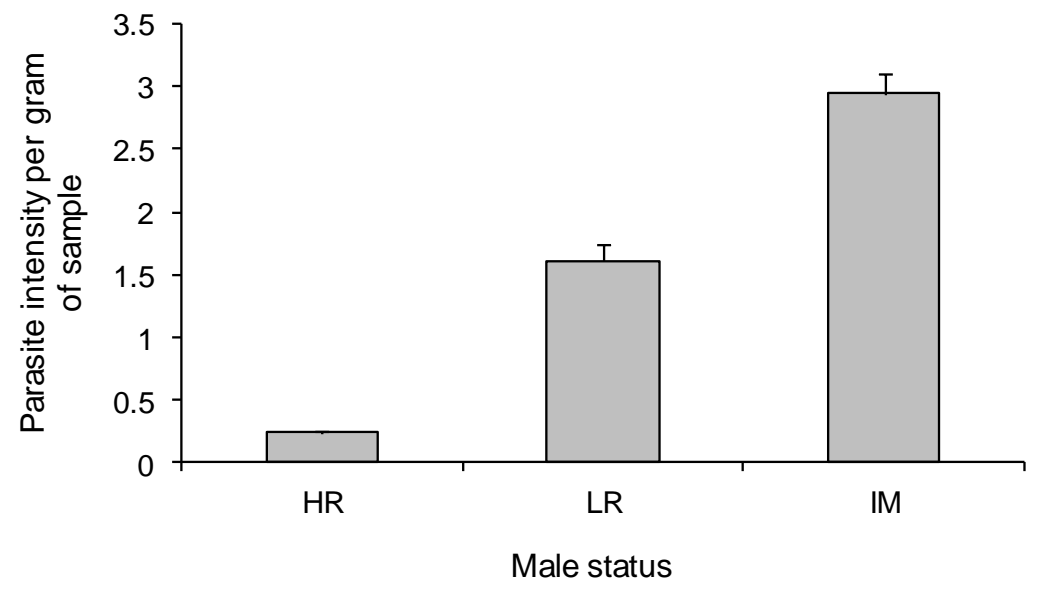

768

769

Fig. 5 Nematode intensity (abundance of parasites per gram fecal sample) in male

770 gray-cheeked mangabeys relative to male status in Kibale National Park, Uganda, 2006-

771 2007. $\mathrm{HR}=$ high-ranking males, $\mathrm{LR}=$ low-ranking males, $\mathrm{IM}=$ immigrant males 
Arlet et al. p. 39

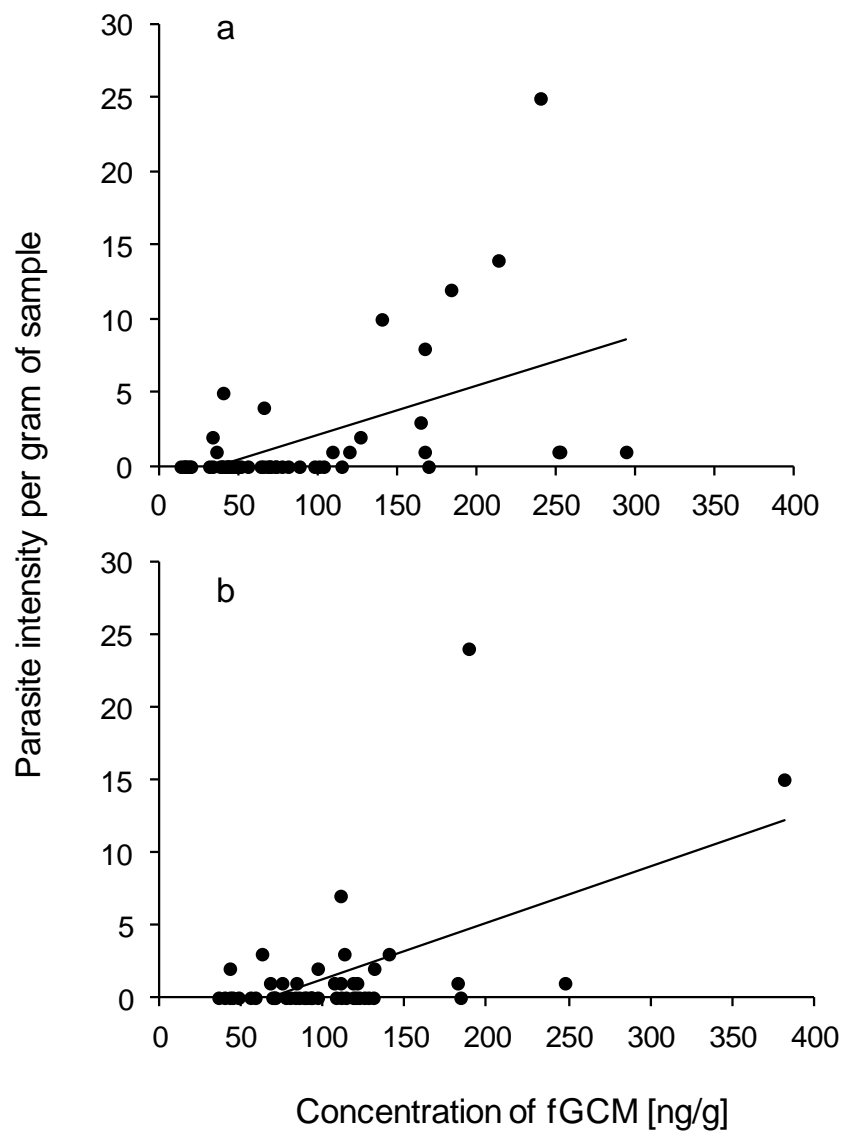

774

775

776 Fig. 6 Nematode intensity (abundance of parasites per gram fecal sample) in male gray-

777 cheeked mangabeys relative to fecal glucocorticoid metabolites: a) when fTM was below

778 the mean of $62.3 \mathrm{ng} / \mathrm{g}$ and b) when fTM was above the mean of $62.3 \mathrm{ng} / \mathrm{g}$

779 
Arlet et al. p. 40

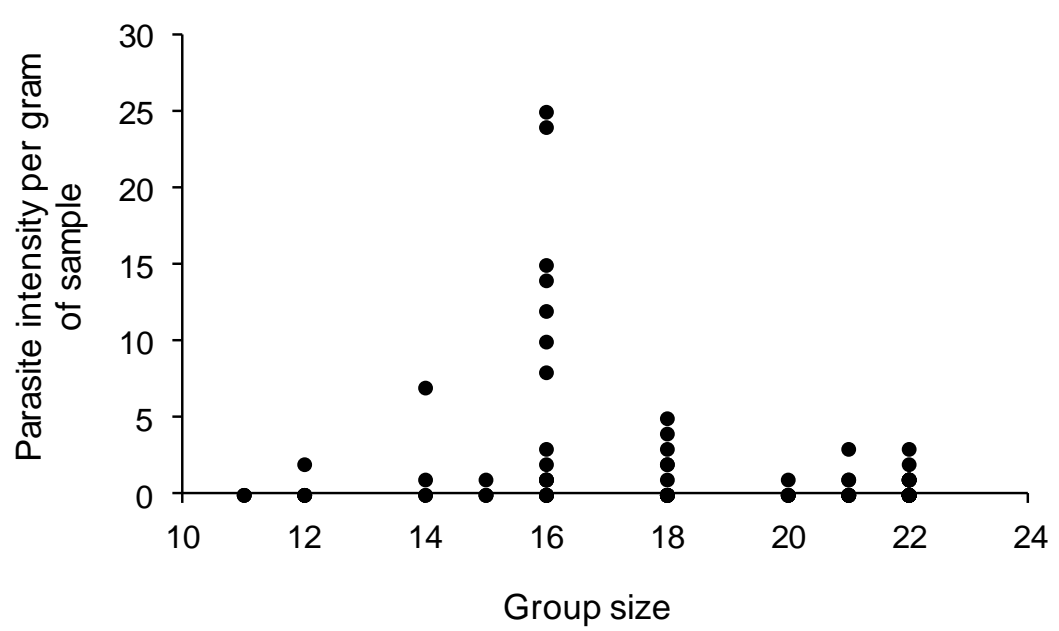

780

781

782

783 Fig. 7 Nematode intensity (abundance of parasites per gram fecal sample) in adult male 784 gray-cheeked mangabeys relative to group size in Kibale National Park, Uganda, 2006-

$785 \quad 2007$

786

787

788

789 
Arlet et al. p. 41

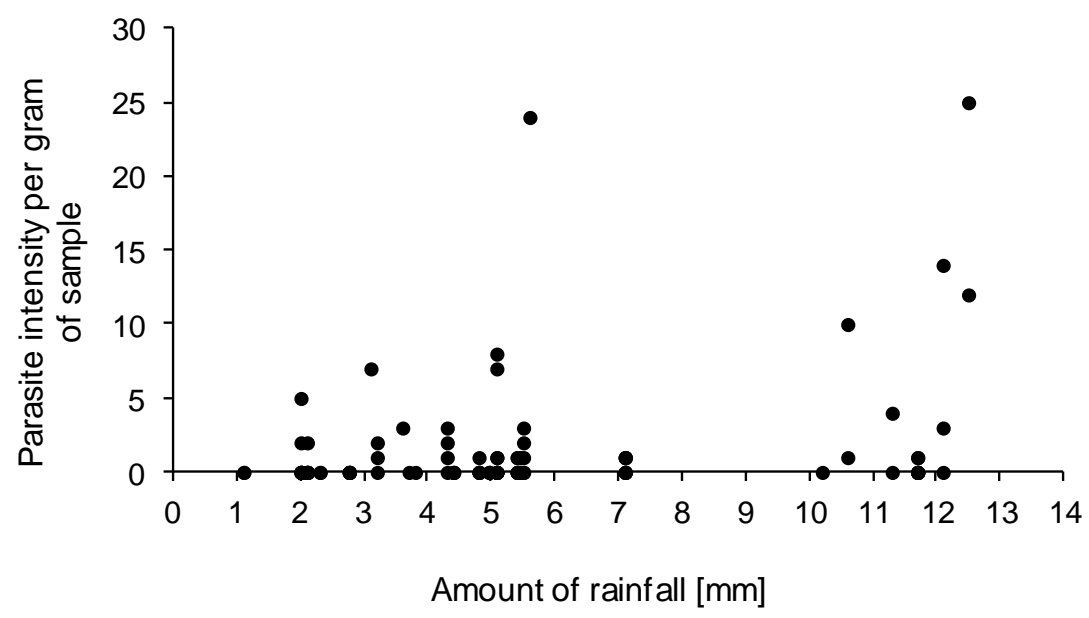

Fig. 8 Nematode intensity (abundance of parasites per gram fecal sample) in adult male

794 gray-cheeked mangabeys relative to monthly rainfall ( $\mathrm{mm}$ ) in Kibale National Park,

795

Uganda, 2006-2007. Each point represents one fecal sample (N=102)

796

797

798

799

800

801

802

803

804

805 
Arlet et al. p. 42

806

807 Table 1. Individual identity, social status (high-ranking male (HR), low-ranking male (LR),

808 or immigrant male (M)), group identity, group size, nematode incidence and intensity, and

809 fecal glucocorticoid (fGCM) and testosterone metabolite (fTM) concentrations among adult

810 male gray-cheeked mangabeys in Kibale National Park, Uganda, 2006-2007.

\begin{tabular}{|c|c|c|c|c|c|c|c|c|c|c|c|c|}
\hline Male & Status & Group & Group size & Incidence $($ mean \pm SD) & Physaloptera sp. & Trichuris sp. & Strongyloidea sp. & Unknown sp. & Intensity & fGCM ng/g $(\operatorname{mean} \pm$ SD $)$ & fTM ng/g $($ mean \pm SD $)$ & Sample size \\
\hline PL & $\mathrm{HR}$ & BT1 & 18 & $0.0 \pm 0.0$ & 0 & 0 & 0 & 0 & 0 & $76.2 \pm 28.4$ & $63.0 \pm 8.9$ & 6 \\
\hline LM & HR & BT1 & 18 & $0.4 \pm 0.6$ & 0 & 3 & 0 & 1 & 4 & $71.1 \pm 16.1$ & $78.8 \pm 3.8$ & 5 \\
\hline PL & LR & BT1 & 18 & $1.0 \pm 0.0$ & 3 & 1 & 3 & 0 & 7 & $36.5 \pm 4.7$ & $60.2 \pm 1.6$ & 2 \\
\hline BG2 & LR & BT1 & 18 & $0.4 \pm 0.5$ & 7 & 0 & 0 & 0 & 7 & $53.8 \pm 9.8$ & $51.8 \pm 7.7$ & 7 \\
\hline $\mathrm{KR}$ & $\mathrm{HR}$ & $\mathrm{CC}$ & 15 & $0.3 \pm 0.6$ & 0 & 0 & 0 & 1 & 1 & $67.8 \pm 25.3$ & $63.3 \pm 3.1$ & 3 \\
\hline MF & HR & $\mathrm{CC}$ & 18 & $0.3 \pm 0.5$ & 2 & 0 & 0 & 0 & 2 & $82.8 \pm 13.5$ & $74.8 \pm 17.3$ & 4 \\
\hline $\mathrm{KJ}$ & LR & $\mathrm{CC}$ & 16 & $0.6 \pm 0.6$ & 25 & 0 & 0 & 1 & 26 & $68.7 \pm 69.4$ & $47.2 \pm 25.7$ & 5 \\
\hline KK & $\mathrm{M}$ & $\mathrm{CC}$ & 16 & $0.7 \pm 0.5$ & 51 & 0 & 12 & 3 & 66 & $137.4 \pm 57.2$ & $50.8 \pm 11.3$ & 10 \\
\hline MF & $\mathrm{M}$ & $\mathrm{CC}$ & 16 & $0.7 \pm 0.5$ & 18 & 0 & 8 & 0 & 18 & $220.5 \pm 107.6$ & $59.1 \pm 23.4$ & 4 \\
\hline MG & HR & LC1 & 22 & $0.0 \pm 0.0$ & 0 & 0 & 0 & 0 & 0 & $110.1 \pm 15.9$ & $93.0 \pm 14.5$ & 7 \\
\hline $\mathrm{R}$ & HR & LC1 & 21 & $0.0 \pm 0.0$ & 0 & 0 & 0 & 0 & 0 & $132.6 \pm 29.7$ & $101.5 \pm 5.6$ & 5 \\
\hline YM & HR & LC1 & 21 & $0.5 \pm 0.6$ & 0 & 0 & 2 & 0 & 2 & $115.3 \pm 47.8$ & $88.7 \pm 8.9$ & 4 \\
\hline MR & LR & LC1 & 22 & $0.0 \pm 0.0$ & 0 & 0 & 0 & 0 & 0 & $28.7 \pm 15.2$ & $43.5 \pm 8.7$ & 6 \\
\hline NK & LR & LC1 & 22 & $0.4 \pm 0.6$ & 1 & 0 & 3 & 0 & 4 & $70.2 \pm 37.7$ & $45.7 \pm 27.8$ & 5 \\
\hline BW & M & LC1 & 22 & $0.4 \pm 0.5$ & 2 & 1 & 4 & 0 & 7 & $98.6 \pm 29.3$ & $60.7 \pm 26.0$ & 8 \\
\hline $\mathrm{HL}$ & M & LC1 & 21 & $0.6 \pm 0.5$ & 2 & 0 & 2 & 0 & 4 & $183.1 \pm 29.3$ & $47.6 \pm 26.1$ & 7 \\
\hline IB & HR & LC2 & 12 & $0.2 \pm 0.5$ & 1 & 1 & 0 & 0 & 2 & $41.8 \pm 4.7$ & $77.9 \pm 13.3$ & 5 \\
\hline NY & LR & LC2 & 12 & $0.0 \pm 0.0$ & 0 & 0 & 0 & 0 & 0 & $33.7 \pm 13.1$ & $19.8 \pm 10.3$ & 4 \\
\hline KY & HR & MK & 15 & $0.3 \pm 0.6$ & 0 & 0 & 1 & 0 & 1 & $71.0 \pm 3.0$ & $74.5 \pm 9.3$ & 3 \\
\hline KC & LR & MK & 14 & $0.5 \pm 0.7$ & 5 & 0 & 2 & 0 & 7 & $82.8 \pm 38.7$ & $65.9 \pm 15.4$ & 2 \\
\hline
\end{tabular}

812

813 Table 2. Results of a GLMM with binomial distribution examining factors associated with

814 parasite incidence in adult male gray-cheeked mangabeys in Kibale National Park, 2006-

8152007.

\begin{tabular}{lccc} 
& Estimate & SE & $\mathrm{P}$ \\
\hline Intercept & -5.30 & 2.20 & 0.022 \\
Status & 4.75 & 3.09 & 0.002 \\
fGCM & 0.03 & 0.01 & 0.001 \\
fTM & 0.09 & 0.02 & 0.001 \\
Group size & -0.43 & 0.12 & 0.001 \\
Rainfall & 0.08 & 0.09 & 0.351
\end{tabular}


Arlet et al. p. 43

818 Table 3. Results of a GLMM with Poisson distribution examining factors associated with

819 parasite intensity in adult male gray-cheeked mangabeys in Kibale National Park, 2006-

8202007.

821

\begin{tabular}{lccc} 
& Estimate & $\mathrm{SE}$ & $\mathrm{P}$ \\
\hline Intercept & 1.080 & 0.720 & 0.140 \\
Status & 3.940 & 3.970 & $<0.001$ \\
fGCM & 0.010 & 0.001 & $<0.001$ \\
fTM & 0.060 & 0.009 & $<0.001$ \\
Group size & -0.280 & 0.040 & 0.011 \\
Rainfall & 0.130 & 0.030 & 0.003 \\
fGCM x fTM & -0.003 & $<0.001$ & $<0.001$
\end{tabular}

822 